\title{
Production, Modification and Bio-Applications of Magnetic Nanoparticles Gestated by Magnetotactic Bacteria
}

\author{
Jin Xie, Kai Chen, and Xiaoyuan Chen $(\bowtie)$ \\ Department of Radiology, Bio-X Program, Stanford University School of Medicine, Stanford, CA 94305-5484, USA \\ Received: 6 December 2008/Revised: 20 January 2009/Accepted: 21 January 2009 \\ (C)Tsinghua University Press and Springer-Verlag 2009. This article is published with open access at Springerlink.com
}

\begin{abstract}
Magnetotactic bacteria (MTB) were first discovered by Richard P. Blakemore in 1975, and this led to the discovery of a wide collection of microorganisms with similar features i.e., the ability to internalize Fe and convert it into magnetic nanoparticles, in the form of either magnetite $\left(\mathrm{Fe}_{3} \mathrm{O}_{4}\right)$ or greigite $\left(\mathrm{Fe}_{3} \mathrm{~S}_{4}\right)$. Studies showed that these particles are highly crystalline, monodisperse, bioengineerable and have high magnetism that is comparable to those made by advanced synthetic methods, making them candidate materials for a broad range of bio-applications. In this review article, the history of the discovery of MTB and subsequent efforts to elucidate the mechanisms behind the magnetosome formation are briefly covered. The focus is on how to utilize the knowledge gained from fundamental studies to fabricate functional MTB nanoparticles (MTB-NPs) that are capable of tackling real biomedical problems.
\end{abstract}

\section{KEYWORDS}

Magnetotactic bacteria (MTB); magnetosome; bio-application; magnetic resonance imaging (MRI)

\section{Introduction}

Magnetotactic bacteria (MTB) were first discovered by Richard P. Blakemore in 1975 [1] when he was looking at some coccoid bacteria and found a large population of them migrating in one direction, which could be reversed under the influence of an external magnetic field. Such magnetic-field-dependent cell movement was unprecedented and soon attracted considerable attention, which led to the discovery of a wide collection of microorganisms with similar features. Subsequent studies showed that those bacteria were all capable of taking up Fe sources and converting them in vivo to magnetic nanocrystals, in the form of either magnetite $\left(\mathrm{Fe}_{3} \mathrm{O}_{4}\right)$ or greigite $\left(\mathrm{Fe}_{3} \mathrm{~S}_{4}\right)$.
Advances in electron microscopy gave us the chance to visualize these imbedded particles. As illustrated in Fig. 1, one can see that they are evenly distributed in size and morphology, and are regularly aligned into chain-like structures. Closer view shows (Fig. 1(d)) that each particle is enveloped by one faint black circle, which is indicative of an organic membrane coating surrounding the nanoparticle core [2]. This membrane is tightly associated with the particles, and is indispensable for particle formation and stabilization. As a whole, nanoparticle and membrane constitute a unique organelle called a magnetosome, which is only found in magnetotactic bacteria and is the hallmark that distinguishes these

Address correspondence to shawchen@stanford.edu 

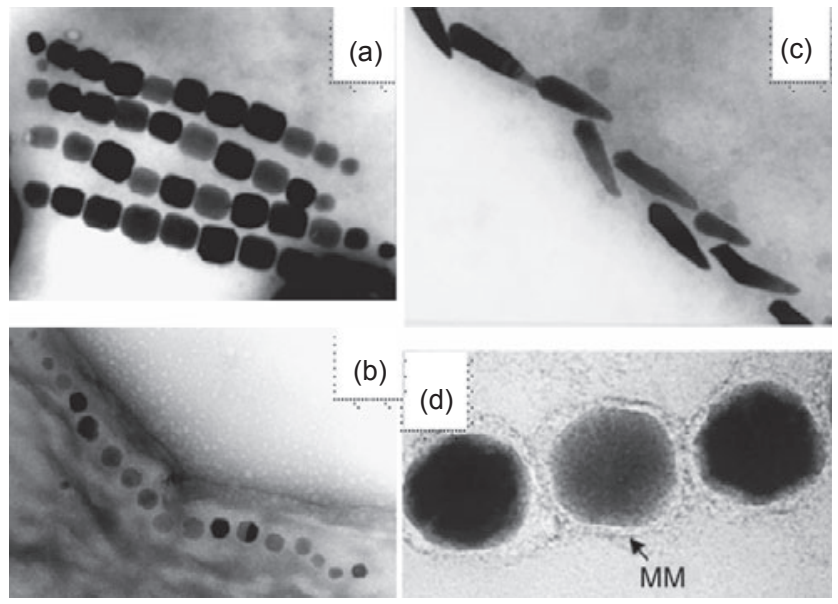

Figure 1 (a)-(c) TEM images of MTB-NPs with different shapes: (a) elongated prisms; (b) cubo-octahedral; (c) bullet-shaped; (d) high-magnification view of MTB-NPs showing their magnetosome membrane (MMs). Copyright@Springer-Verlag. Reproduced from Ref. [2] with permission

bacteria from other prokaryotes.

In the early days of MTB research, most studies were conducted to address questions such as how the magnetic crystals were made and aligned, how the MTB controlled the biomineralization, and why bacteria containing such organelles evolved. Nowadays, however, with the rapid development of nanoparticle-based biomedicine, new possibilities for exploiting novel biomaterials have arisen, which encourages us to take a second look at these "old" magnetic materials, but with a new question in mind: could we take advantage of the inexhaustible labor of MTBs to fabricate biomaterials with specific magnetic and biological properties, by precise genetic and proteomic manipulation? In this review article, the history of MTB discovery and subsequent efforts to elucidate the mechanisms behind magnetosome formation will be briefly covered, but the focus will be on how to utilize the knowledge gained from such fundamental studies in order to prepare functional MTB nanoparticles (MTB-NPs) that are applicable to tackle real biomedical problems.

\section{Common MTB features}

MTBs as a whole share some common features. All the reported MTBs are gram-negative members of the domain bacteria. Moreover, all MTBs have only the respiratory form of metabolism, metabolizing short-chain organic acids as carbon sources [3, 4]. Since MTBs are virtually a heterogeneous prokaryote collection constituted by members from different conventional phylogenetic groups, they are inevitably varied in many respects. For example, MTBs with different kinds of morphologies have been reported, including coccoid, rod-shaped, vibrioid, spirilloid, and even multicellular $[1,5,6]$; furthermore, the MTB-NPs that are imbedded in them can differ in size, shape, and orientation [5, 7] Despite this versatility among strains, the properties of MTBNPs are highly strain-specific. Under proper growth conditions, the imbedded particles will develop the desired morphologies and properties, implying the existence of a regulation mechanism.

Thomas-Keprta et al. [8-10] have identified six properties that they claimed as collectively unique for MTB-NPs, which are: (1) unusually truncated hexa-octahedral morphology; (2) few crystallographic defects; (3) elongated habit; (4) narrow size distribution, restricted mainly to the single domain field; (5) high purity; and (6) alignment in chains, with the last being the most distinguishing one [11]. It has now become a general consensus that the significance of aligned magnetic crystals is that it allows maximization of magnetization. By aligning in a head-to-tail manner, the MTBs aggregate their internal magnetic dipole moments, making themselves more susceptible to an external magnetic field [12]. Probably for the same reason, if more than one such magnetosome string exists in a single MTB, they are always found arranged in parallel to each other $[5,6,13]$. Although a single particle is inefficient, such assemblies make each MTB a small compass that is sensitive enough to sense a geomagnetic field, which directs its movement. The bacteria movement that Blakemore observed was a vivid demonstration of the migration of MTBs along the geomagnetic field line, which is one-way, with the specific direction determined by which hemisphere they are in. In particular, MTBs found in the Northern Hemisphere are mostly northseeking MTBs, whilst those found in the Southern Hemisphere are mostly south-seeking. As for those living at the equator, their movements are found 
evenly distributed between the two polarities $[4,7$, $14,15]$. However, such a simple generalization was recently contravened by the finding of a distinct population of south-seeking bacteria in the Northern Hemisphere [7, 16].

This geomagnetic field-governed migration is believed, in one way or another, to benefit the lifestyle of the MTB and, specifically, facilitate their search for optimal living environments in complex chemical gradients, such as aquatic columns with stratified sediments. Based on the fact that MTBs are only populated in narrow bands within the column, it is speculated that the vertical vector of the geomagnetic field can govern the migration of MTBs which helps to simplify their journey from three-dimensional to one-dimensional $[15,17]$. If this model is correct, all the MTBs should be found at the bottom, by virtue of their persistent descending migration. However, some MTBs, especially those producing magnetite crystals, are found to populate in the oxic-anoxic transition zone, located at the middle of the column. This indicates the inadequacy of the previous model and suggests the existence of other parameters that also take part in locating the best living conditions. To address this issue, Taylor et al. conducted an experiment in which they monitored the movement of MTBs in a tube mimicking a stratified semi-anaerobic environment [17]. As shown in Fig. 2(b), an $\mathrm{O}_{2}$ gradient is present in the tube, descending from left to right, with the middle of the tube devised as the optimal oxygen concentration for MTB growth; on the other hand, an external magnetic field is applied with a reverse gradient, from right to left. If the aforementioned model is correct, the MTBs, in this case Magnetospirillum magneticum AMB-1, would keep moving down the magnetic field lines and end up accumulating at the left extremity of the tube. However, it was found that the MTBs were most populous at the middle of the tube [4, 17]. In another demonstration by Whiteman et al., wild-type AMB-1 cells and their nonmagnetic mutant counterparts were put in an environment with an advancing oxygen gradient. It was found that in an applied magnetic field, the wild-type AMB-1 cells migrated faster to the preferred oxygen concentration than either wild-type cells in a zero field or the nonmagnetic cells in any field [18]. Such observations indicate that, besides undergoing geomagnetic field regulation, MTBs are capable of sensing crucial environmental changes, such as oxygen concentration, and correspondingly adjusting their direction of motion to remain within the optimal living conditions. In other words, the migration of MTBs is decided by multiple elements with the motif of finding the best living conditions. It is single-dimensional, but is not necessarily singledirectional. In this sense, the traditional terminology "magnetotactic" is incomplete. For those MTBs which hold positions in the oxic-anoxic zone, both the

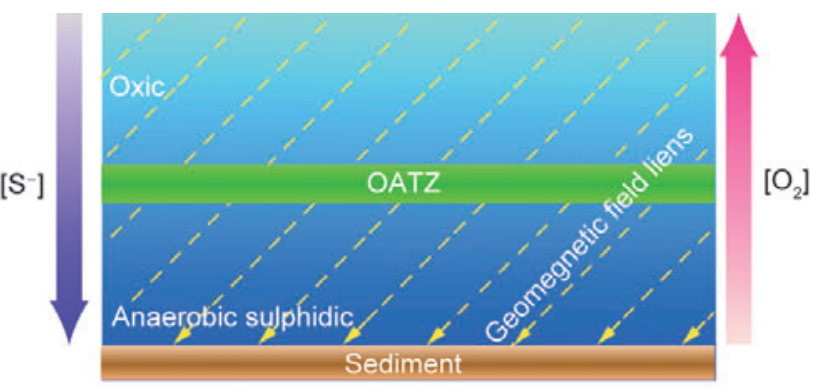

(a)

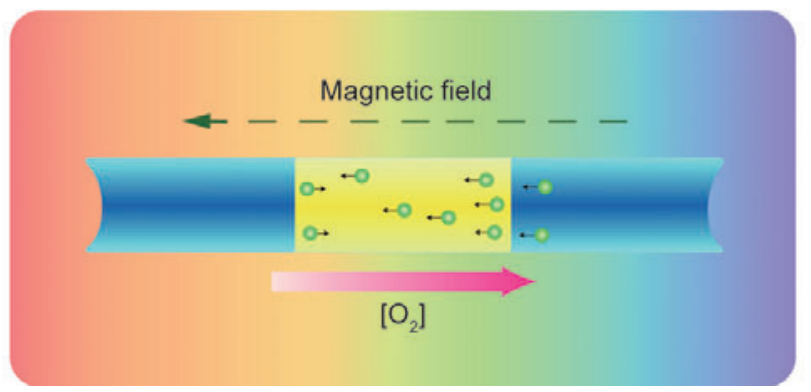

(b)

Figure 2 (a) A representative water column with a chemicallystratified semi-anaerobic environment. Two chemical gradients exist: one is the oxygen concentration, decreasing with depth below the surface; the other one is sulfide concentration, which is a maximum at the sediment where sulfate-reducing bacteria are rich. Most magnetite-producing MTBs are found at the oxic-anoxic transition zone (OATZ) while greigite-producing MTBs are typically found at the anoxic area at the bottom of the column. (b) Tube mimicking a chemically-stratified environment, with the center area being optimal for MTB growth i.e., the OATZ. The oxygen level decreases from the left to right; meanwhile, a magnetic field is applied from right to left. If the magnetic field was the only effect, the MTBs in the tubing should migrate consistently to left. However, the MTBs were found to accumulate in the OATZ, indicating that they could sense the oxygen level change, and adjust their migration correspondingly to maintain themselves in the optimal growth environment 
magnetotaxis and the aerotaxis contribute; hence, the more appropriate designation is "magneto-aerotactic" [5].

In a real aquatic column environment, there exist two essential gradients that descend vertically in the opposite sense: one is oxygen concentration, a maximum at the water surface and gradually decreasing with depth; the other is sulfide concentration, rich in the anaerobic zone at the bottom where sulfate-reducing bacteria are populated while decreasing with increasing altitude. For magnetite-imbedding MTBs, it is the oxic-anoxic transition zone that favors their growth, whilst for the greigite-imbedding ones, it is the lower anaerobic zone that is optimal for their proliferation (Fig. 2).

Interestingly, the apparently identical converse migrations of the MTBs can be powered by different engines. For magnetotactic spirilla, the bidirectional movement is powered by the two polar flagella at both ends of the cells. However, in the case of magnetotactic cocci, turning-around is achieved by reversing the rotation direction of the flagella. In both hemispheres, counterclockwise rotation of magnetotactic cocci will induce motion of the particle towards the pole, whereas clockwise rotation will reverse the direction of motion, which helps the MTBs stay within the zone for optimal growth.

\section{Proteins and lipids associated with magnetosomes}

The MTB-NPs are born with an magnetosome membrane (MM) that stabilizes the particles under the physiological environment. The MM is mainly composed of phospholipids, $50 \%$ of which is pho sphatidylethanolamine, similar to that of the cell membrane (CM) [19]. The MM protein constitution was also found to be similar to that of the CM. For instance, analysis of the complete genome sequence of AMB-1 identified $78 \mathrm{MM}$ proteins that are also prevalent in the CM $[20,21]$. These similarities led to the surmise that the MM might originate from the $\mathrm{CM}$ rather than being generated internally as an independent vesicle [20]. Authentic proof was obtained by electron cryotomography $(\mathrm{ECT})$, which allows visualization of the sample in a three-dimensional manner without fixation or other pre-treatment, thereby giving more detailed and dynamic information [7, 22-24]. Komeili et al. actually captured the invigilating MM, which confirms the above hypothesis [22, 25]. Meanwhile, the observation of empty or partially filled MMs in iron-starved or "pre-magnetic" cells suggests that the MMs are formed prior to the particles and likely work as nanoreactors in which the iron resources are accumulated and subsequently converted into particles under controlled conditions $[19,26]$.

ECT imaging also helps in understanding the formation of chain-like assemblies of the magnetosomes. The magnetite crystals imbedded within these liposomes are beyond the superparamagnetic region [26], and therefore have a tendency to aggregate due to strong magnetic interactions. Given that they are actually lineally aligned, there must exist another stabilizing force or scaffold upon which the particles are positioned. High-resolution ECT images confirmed such postulation by finding a filament (Fig. 3) which crosses every $\mathrm{MM}$ and transverses the cell in a poleto-pole manner. Therefore, like pearls strung on a necklace, the MMs are positioned on the string, in a regular manner without aggregation. Early time observations show that the MMs grow separately on the filaments in the beginning. With the subsequent growth of the particles, there is a concomitant increase in the magnetic interactions between them,
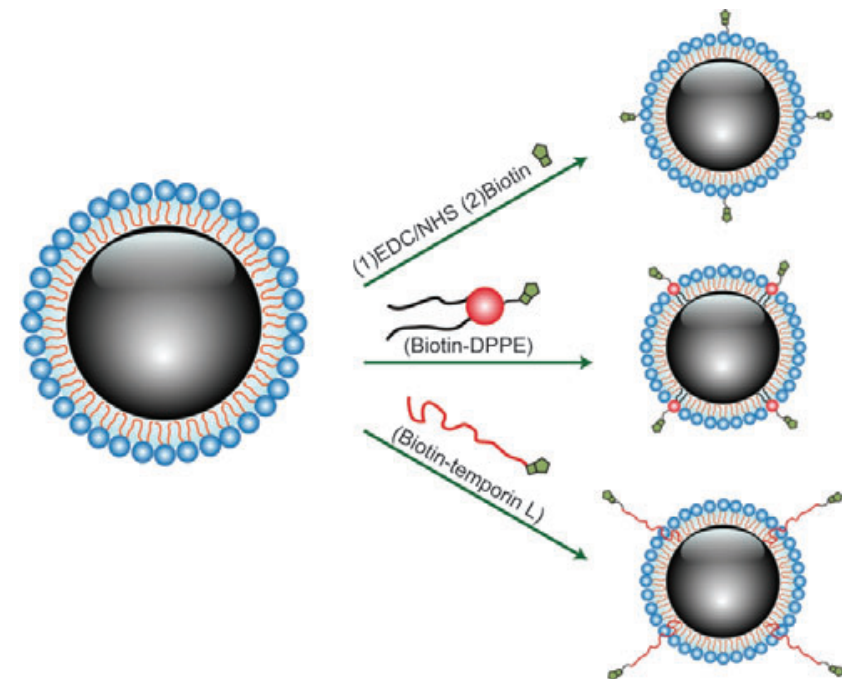

Figure 3 MTB nanoparticle biotinylation with chemical coupling, biotin-DPPE insertion and biotin-temporin $\mathrm{L}$ insertion 
which brings them closer and ultimately results in the head-to-tail linear assembly.

Despite the similarity in composition of $\mathrm{MM}$ and $\mathrm{CM}$, many kinds of proteins are only found on the MM surface. Some of these proteins are involved in the particle biomineralization and assembly, so an understanding of their roles is the key to modulate the MTB-NP formation at the proteomic and genetic levels. This is facilitated by the fact that the genomes of some MTBs have been completely (magnetospirillum magneticum strain AMB-1 and magnetic coccus MC-1) or almost completely (magnetospirillum gryphiswaldense strain MSR-1 and magnetospirillum magnetotacticum strain MS-1) sequenced [27]. For example, the genome sequence of AMB-1, which consists of a single circular chromosome of 4,967,148 bp and 4559 predicted open reading frames (ORFs), has been completely deciphered [21]. Of the genes that encode for MM proteins, 48 have been identified as MTB-specific, 13 of which are believed to take part in the MTB formation.[21]. Previously, a $130 \mathrm{~kb}$ magnetosome genomic island was identified, which is referred to as the "magnetosome island" (MAI) [26, 28-30]. Most of the identified magnetosome specific proteins (such as MamA, MamB, MamC, MamD, and MamE) were found grouped into gene clusters within the MAI [7]. For instance, Grunberg et al. found two gene clusters: the first one was constituted by 17 genes including $m a m A, m a m B$, and mamE genes; the second one was a four gene cluster, containing mam $C$ and mamD [31]. It was thought that the genes in MAI might be adequate for magnetosome formation [7]. However, a gene comparison analysis conducted recently by Schuler et al. on four kinds of MTB genomes (AMB-1, MC-1, MS-1, and MSR-1) found 28 shared genes which had exhibited no, or only remote, similarities to any genes from more than 426 non-magnetotactic bacterial and archaeal genome sequences [27]. While 18 of these genes are located in MAI, 10 of them are outside MAI, suggesting that MAI genes are not sufficient for MM formation. One possible explanation is that while the genes necessary for biomineralization are confined in MAI, those responsible for the "taxis" part are less conservative and are distributed outside MAI [27].
Knowing the genome sequence is valuable in allowing interrogation of the protein functions at genomic and proteomic levels, which, however, is nontrivial. One approach is to knock out the gene of interest, and deduce the protein function from the abnormalities displayed by the resulting mutant, which are probably caused by the protein absence. For instance, in the $\Delta m a m J$ mutant of MSR-1 cells, while the amounts of the magnetosomes, the cytoskeleton filament and the MTB-NP structure remain the same, the chain-like assembly disappears; instead, the magnetosomes are found aggregated in the cytoplasm [23]. From such observation, we know that the MamJ must contribute to the connection between magnetosomes and the cytoskeleton filament, and although the filament remains intact, the absence of MamJ as the "glue" causes dissociation of the magnetosomes from the string; without the holding tension, the magnetic forces bring the magnetosomes together [23,32]. In the case when MamK was absent, a slightly different phenomenon was observed. The magnetosomes in the $\Delta m a m K$ mutant, while also failing to form a linear alignment, were found dispersed in the cytoplasm instead of forming aggregates [22]. Clearly, MamK also takes part in the magnesotome-filament conjugation, but plays a different role. Schuler et al. showed that GFP-fused MamK displayed a filament-like arrangement which spanned the whole cell, with a profile resembling that of the filament, indicating that MamK is closely related to the cytoskeleton filament [23]. This hypothesis was supported by another observation made by $\mathrm{Wu}$ et al., who labeled MamK with dual fluorescent probes and tracked their formation, finding that the MamK protein nucleated at multiple sites in the cytoplasm and gradually assembled into mosaic filaments [33]. In addition, it was found that gene mamK alone is efficient in directing the synthesis of linear filaments in E. coli [33]. Based on these observations, a rationale was suggested for the magnetosome chain formation, in which MamK is described as the main component of the cytoskeleton filament, and MamJ is closely associated with MamK and helps maintain the magnetosomes on the filament. However, the exact functions of MamJ and MamK, as well as how they

\section{Springer}


interact with each other, are still largely unknown. Furthermore, such a model does not explain the different magnetosome arrangment profiles in $\triangle m a m K$ and $\triangle m a m J$ mutants.

Similar strategies have been employed with other MM proteins to elucidate their roles in the biomineralization. For instance, $\Delta m a m A$ cells were found to be less efficient in taking up iron and forming magnetite crystals; they also possessed shorter magnetosome chains compared with the innate ones [25]. Based on those observations, it was suggested that MamA might take part in sorting of the magnetosome protein or in activating a response to external cues; alternatively, they could be involved in a more specific strategy in regulating the length of the magnetosome chains, in response to the iron supply and other environmental conditions [25]. In another study by Schuler et al., $\triangle m a m G F D C$ mutant was obtained and analyzed [34]. MamG, MamG, MamF, and MamC altogether make up 35\% of the total MM proteins, and are anticipated to contribute to the particle growth. Neither deletion of mamC, which encodes the most abundant MM protein, nor of mamGFDC resulted in failure to form magnetite crystals. However, in the latter case, the magnetite crystals were only $75 \%$ of the wild-type size and were less regular. Although the detailed functions of the four proteins in biomineralization remain elusive, it has been suggested that they might play redundant roles in the process of particle growth [34].

Despite the recent breakthroughs, what has been learned might be just the tip of the iceberg, and it is still too early to claim a full understanding of the MTB biomineralization and chain assembly at genomic and proteomic level. There are so many uncertainties that we are still unable to answer some basic questions, such as exactly how the magnetosome vesicle formation is initiated, how the $\mathrm{Fe}$ is accumulated and how the magnetosomes interact with the filament, not to mention the detailed descriptions of the respective and collective functions of the different MM proteins. However, with new state-of-the-art techniques and the successful sequencing of MTB genomes [21], such studies are making rapid progress. More importantly, the results obtained from these fundamental studies have already began to increase interest in magnetosomes as a novel class of materials.

\section{Magnetosome magnetic crystals}

MTB-NPs are the cores of the magnetosomes, literally and figuratively. Compared with conventional magnetic particles made by chemical synthesis, MTB particles have many interesting attributes.

Narrow size distribution. The synthesis of magnetic nanoparticles has been well documented, developing from physical approaches to chemical approaches, and recently from aqueous solution based-approaches to organic solution-based pyrolysis, with the purpose of giving better control over particle size, shape, and physical properties. It is only recently, however, that we can make artifical particles with comparable monodispersity to MTBNPs.

Better shape control. In laboratory synthesis, it is more difficult to control the shape of magnetic nanoparticles than other materials, such as quantum dots or noble metals. Most of the chemically synthesized magnetite particles are spherical or polygonal or simply a mixture. On the contrary, the morphology of MTB-NPs are species-specific and vary among strains, with cuboidal, parallelepipedal, and tooth, bullet- or arrowhead shapes all being reported $[5,35,36]$.

MTB-NPs are typically highly crystalline with few defects [37]. Although it is possible to synthesize magnetic nanoparticles with good crystallinity, it typically requires high-temperature treatment; MTBs, however, can achieve this at room temperature. Studies have shown that MTBNPs are always constituted of a combination of octahedral [111], dodecahedral [110], and cubic [100] forms $[38,39]$. How the shape control is achieved is unclear so far, but based on our knowledge of the growth of synthetic particles, it could be due to the selective inhibition of specific faces by adsorption of certain organic molecules. Another interesting phenomenon is that the MTB particles are inclined to align themselves along a specific axis, which differs for magnetite and greigite particles. In the case of magnetite particles, they align along the [111] 
direction $[38,39]$ whereas for greigite particles, the alignment is along the [100] direction.

Specific size range. Current magnetic nanoparticle synthesis focuses more on yielding particles with size ranging from 5-20 nm, in which scale the particles are known to be superparamagnetic, i.e., retaining zero magnetic moment without an external magnetic field. Larger magnetite particles with higher magnetization per particle could be advantageous in applications such as magnetic separation and MRI. However, being ferromagnetic, their stabilization becomes more challenging which might be the main reason why their chemical synthesis has rarely been reported. In contrast, the sizes of MTB-NPs usually range from 35 to $120 \mathrm{~nm}$, a scale not attainable for chemically synthesized NPs. It is worth pointing out that the fact that MTB particle size falls in this region is unlikely to be a coincidence. Magnetite particles with sizes below $20 \mathrm{~nm}$, being superparamagnetic, could not respond to a geomagnetic field. On the other hand, those with sizes larger than $120 \mathrm{~nm}$ inevitably possess multiple magnetic domains, which point at different directions and could compromise the overall magnetization. The largest MTB particles reported so far possess a size which correlates well with the theoretical critical size for the single-domain-multi-domain transition [40], indicating that the specific size range of MTB particles might be an evolutionary choice, allowing them to serve as a compass and guiding cell migration under a geomagnetic field. Please note that the regularity of size, shape, and side distribution we refer to here is based on the assumption that all the growth conditions are satisfied. If not, the actual particle shape control can be severely compromised, as many parameters, such as oxygen concentration, iron supply, and rate of growth can affect the final particle morphology [41].

Better $T_{2}$ reducing effect. Small magnetic nanoparticles (especially those smaller than 20 $\mathrm{nm}$ ) usually suffer from spin surface disorders and spin canting, which might severely temper the magnetization [42]. In this sense, the MTB-NPs have advantages over small synthetic analogues in possessing close-to-bulk magnetizations [37, 43] therefore potentially inducing more prominent $\mathrm{T}_{2}$ reducing effects. Herborn et al. found that the transverse relaxivity of the magnetosome magnetite was $146 \mathrm{mmol}^{-1} \cdot \mathrm{s}^{-1}$, compared to a value of $62 \mathrm{mmol}^{-1} \cdot \mathrm{s}^{-1}$ for synthetic magnetite particles with a dextran coating [42].

Biologically catalyzed particle formation. As already mentioned, the MTB crystals have few defects which, in the case of chemical based synthesis, is only possible when treating the Fe precursor at high temperature. Such capability was once attributed to a long, multiple-step biomineralization process. However, recent studies showed that it only takes 30 min for MTB to form mature magnetite crystals: in the first $15 \mathrm{~min}$, the crystals grow to the desired size, but with a nonmagnetic surface layer constituted by hematite; then in another $15 \mathrm{~min}$, such hematite phases are completely converted to magnetite, with a concurrent increase in magnetization [44]. How the MTBs control this process to achieve the desired particle size and shape is still a mystery, but it is very likely that some proteins are involved in the formation process by interacting with the surface of the growing particles. For example, Mms6 is an MM protein found with high iron affinity. In an in vitro test, Mms6 alone is demonstrated to be effective in forming uniform $30 \mathrm{~nm}$ magnetite particles, and is believed to play important roles in in vivo particle formation [45]. Many other MM proteins, such as the aforementioned MamC, MamD, MamF, and MamG, also seem to participate in the biomineralization process, as the corresponding knocked-out mutants give particles which are smaller and less regular in morphology [34].

The composition of the MTB-NPs is highly conservative [46]. Unlike chemical synthesis, in which magnetite alloys can be easily made by mixing the Fe precursor with other metal salts, efforts to make doped MTB-NPs by simply growing MTB with multiple cations are usually fruitless: the cells can selectively take up iron from even limited supplies to make pure magnetite particles [47]. The mechanism of this specific uptake is still unknown. As a matter of fact, there is hardly any proof of the origin of such a distinct iron uptake pathway in MTB [48], although they can accumulate iron up to $4 \%$ of their dry weight. Fe(II) can be assimilated through a central ferrous transporter and simple diffusion, or, 
alternatively, from reduction of $\mathrm{Fe}(\mathrm{III})$; the latter is supported by the findings of certain ferric reductases [49-51]. On the other hand, Fe(III) uptake is probably facilitated by forming complexes with certain chelating agents called siderophores produced by MTBs, most of which are catecholates and hydroxamates [5]. In a study conducted with AMB-1, it was found that three ferrous iron transport genes$f t r, t p d$, and $f e o$ - were all up-regulated when grown under iron-rich conditions, whereas four ferric iron transport genes-fep $A$, ton $B, \operatorname{exb} B$, and $e x b D$-were found to be down-regulated [48, 52]. Meanwhile, a ferric siderophore outer membrane receptor $\operatorname{cir} A$, and an inner membrane ferric siderophore transporter $f e p C$, were found to be up-regulated under such ironrich conditions $[48,52]$, which seems to correlate with the siderophore-facilitating mechanism. Schuler et al. proposed another model [53, 54], in which both $\mathrm{Fe}(\mathrm{II})$ and $\mathrm{Fe}(\mathrm{III})$ cations pass from $\mathrm{CM}$ to $\mathrm{MM}$ without iron transport. These cations are presumably ligated with organic substrates at the CM level, and are subsequently released at the magnetosome interface, where co-precipitation occurs and particle nucleation is initiated. The organic substrate for ferric conjugation can be ferritin; the substrate for ferrous conjugation is unknown, however [54]. Internally, some MM proteins may be involved in the iron accumulation. For example, two MM proteins-MamB and MamM-structurally resembling the $\mathrm{CDF}$ family are putative Fe transport proteins $[28,55,56]$. A mutant of $M$. gryphiswaldense, which lacks MamB, MamM as well as some other MM proteins, was found to be deficient in Fe uptake [28]. Inspired by the siderophore-assisted iron uptake mechanism, in a recent effort, Ward et al. mixed cobalt quinate into the incubating medium, and successfully doped up to $1.4 \%$ cobalt into the MTB-NPs. Such doping dramatically altered the magnetic properties of the particles, resulting in a $36 \%-45 \%$ increase in coercivity [47]. Such a doping strategy might be applicable to other kinds of cation doping as well.

Again, strict biogenic control over the particle characteristics is based on the assumption that the optimal growth factors are satisfied. Otherwise, the bio-mineralization process is not necessarily as robust and can be dramatically influenced by many external parameters [57]. It is also worth noting that, as a heterogeneous group, even when the conditions are optimal, there are some exceptions, for which the general features do not hold. For example, a rodshaped bacterium was found by Hanson et al., in which both magnetite and greigite particles were produced, with the former being arrowhead-shaped and the latter being rectangular prismatic, and were co-assembled into one chain. The actual particle composition depends upon the surroundings: those growing in the oxic-anoxic transition zone predominantly yield magnetite particles whilst those growing in the anaerobic region, where sulfide supply is abundant, yield exclusively greigite particles [58]. There have also been reports of the discovery of crystals with other compositions, such as cubic FeS, tetragonal FeS, and pyrrhotite $\left(\mathrm{Fe}_{7} \mathrm{~S}_{8}\right)$. However, these phases are non-magnetic and hence are unlikely to help cells locate the optimal growing environment. It has been suggested that these might just be precursors of $\mathrm{Fe}_{3} \mathrm{~S}_{4}$ [4].

Compared with greigite nanoparticles, magnetite nanoparticles have higher magnetization and thus are more useful for potential practical applications in bio-separation, hyperthermia and as contrast agents in MR imaging; furthermore, no iron sulfide MTB has been successfully isolated in a pure culture. Therefore, for the remainder of this review, we will focus the discussion on magnetite MTBs only.

\section{Production and purification of MTB-NPs}

As aforementioned, the MTB-NPs are favored over synthetic analogues by virtue of their superior magnetic properties and bio-tailorabilities, and so the idea of culturing MTBs to produce magnetic nanoparticles has long been discussed. However, advances in utilizing MTB-NPs for practical usage have been slow, which is in great part due to the limitations on production.

Unlike the production of other common biomaterials, the purification step, which usually takes considerable effort, is a minor issue for MTBNP production. Owing to their magnetic features, the MTB-NPs can be easily concentrated and 
separated, in an innate state, along with the lipid layer and the MM proteins. On the occasions when only the magnetic cores are required, the collected magnetosomes are treated with detergents, which strip the lipid coating layer and yield bare magnetic particles. It should be noted, however, that the deprotected particles tend to form aggregates because of mutual magnetic attraction, until a new coating is supplied [59].

In contrast, the growth of MTB under laboratory conditions is non-trivial. One of the biggest issues is that most MTBs prefer complex chemically stratified aquatic habitats and vertical redox gradients, which are very hard to mimic in the laboratory [2]. Furthermore, it is challenging to sustainably maintain the optimal growth parameters in a closed system. For example, oxygen concentration, is one of the most critical parameters in MTB proliferation. Either too high or too low an oxygen concentration has been proven to inhibit the bacteria growth, thus the oxygen needs to be set precisely at a microaerobic level. Even if the initial oxygen concentration is at the optimal level, it will drop as it is consumed by cell respiration, and this eventually inhibits the cell growth. The solution to this is to connect the incubation system to a sensitive oxygen detector which can regulate the oxygen input and keep oxygen at a constant level. If multiple parameters need to be monitored and controlled, the resulting system is extremely complicated. This explains why only a few MTB strains have been successfully cultured in the laboratory.

The most common and compliable MTB strains are AMB-1, MRS-1, and MC- 1 . In a study performed by Schuler et al., in order to find the optimal growth conditions, all three strains were cultivated in a modified dual-vessel laboratory fermentor [40]. Unlike the common fermentor, such a system is connected to an oxygen probe, which can continuously monitor the change in oxygen concentration and consequently regulate the oxygen input valve. It is also equipped with automatic $\mathrm{pH}$ and temperature controls, making it an ideal platform to study in detail how these parameters affect the MTB growth and MTB-NP production. Regarding oxygen concentration, it has been shown that the MTB began to efficiently produce MTB-NPs only when the oxygen partial pressure, $p\left(\mathrm{O}_{2}\right)$, was below 20 mbar. Within the $p\left(\mathrm{O}_{2}\right)$ regime they studied, there was a clear trend that decreased oxygen levels facilitated production of the MTB-NPs. On the other hand, however, too low an initial oxygen concentration limited cell growth. The optimal $p\left(\mathrm{O}_{2}\right)$ value according to the study was 0.25 mbar for all the three strains, which was the lower detection limit of the system; at this oxygen level, the highest MTBNP yield record was $6.3 \mathrm{mg} / \mathrm{L}$ per day, which was achieved by strain MSR-1 [40]. A further decrease in the oxygen concentration might lead to a higher yield, but this was not possible to ascertain, due to the detection limit of the apparatus. Later, Li et al. conducted a similar study with the same system, but instead of depending on an oxygen regulator, which is not sensitive enough, to maintain the oxygen level, they did it by monitoring the cell growth. In a closed fermentor, the MTB growth was inhibited once the oxygen level dropped below the optimal range, and they found that increasing the stirring speed could help restore the growth. After subsequent oxygen consumption by metabolism, growth once again slowed down, and could be restored by a further increase in stirring speed; this pattern could be repeated several times. In this way they managed to grow MTBs in a much lower oxygen concentration without severely inhibiting the cell growth. The yield of MTB-NPs from MSR-1 was elevated to be $16.7 \mathrm{mg} / \mathrm{L}$ per day, [60].

\section{Surface modification and bioapplications of MTB-NPs}

Application of iron oxide nanoparticles for biomedical usages, such as MR imaging, drug delivery and bioseparation, have attracted much attention in the past two decades. Most of the studies have been carried out with synthetic particles. As mentioned previously, the superb magnetic properties of MTB nanocrystals, such as monodispersity, high crystallinity and close-to-bulk magnetization, allow them to compete with or even surpass those made by state-of-the-art synthetic routes. Their innate physiological compatibility, i. e., their nontoxicity 
and stability, is preferable to the synthetic analogues. In addition, MTB-NPs disperse well in water owing to their innate lipid coating, whereas the synthetic particles need to be rendered water soluble, which is usually nontrivial and can be extremely difficult for those with sizes beyond the superparamagnetic range.

In the context of bioapplications, one major concern is the functionalization of the particles. For specific bioapplications, the particles usually have to be loaded with biomolecules, such as DNA, proteins, and peptides, in order to be equipped with the relevant pathophysiological capabilities. The lipid layer on the particles provides a nice platform, which permits the immobilization of biomolecules through a variety of bionconjugation techniques. Taking biotinylation for example, as mentioned earlier, phosphatidylethanolamine accounts for $50 \%$ of the total phospholipid content of the MM coating [19]; this is amine terminated and can be readily coupled with biotin forming amide bond [61]. The resulting biotinylated magnetosomes can induce streptavidin immobilization through the well-known biotin-streptavidin interaction, and since streptavidin has four identical binding sites, they can serve as bridge molecules to allow the introduction of another biotinylated biospecies. Alternatively, biotinylation can be done by direct insertion, referring to the approach of adding biotinylated lipids into the coating layer. Driven by the conformity in structure and amphiphilicity, the newly added biotinlyated lipid, such as biotin-DPPE, can self-assemble into the existing coating layer, by simple mixing. Niemeyer et al. tested and compared both methods and found that the biotin-DPPE insertion approach was about two to three times more effective in biontinylation than the chemical conjugation approach, as was the subsequent streptavidin loading step [61]. Specifically, on each MTB particle, about 120 streptavidins could be loaded by adopting the lipid insertion method, whereas chemical conjugation only gave up to 40 streptavidins per particle. In a similar manner, other kinds of amphiphilic molecules can also be immobilized onto the lipid coating layer. For instance, temporin $\mathrm{L}$, an amphiphilic peptide, has been used to introduce biotins onto the MM surface, allowing the hydrophobic C-terminus to be intercalated into the MM, while leaving the biotinylated N-terminus exposed on the MM surface (Fig. 3) [3, 62].

Another successful approach to realize functionalization, which is unique to MTB-NPs, is through genomic and proteomic manipulation. This is facilitated by the ongoing advances in proteomics and genetics, which have made it possible for us to engineer the MM protein sequence and fuse it with certain reporter genes. The reporter gene encodes protein and peptide, which serves as an effective receptor to favor subsequent immobilization or as an active probe to allow interrogation of the fused MM proteins. The selected MM proteins are usually those with high expression levels, in most cases MagA, Mms13 and Mms16 (Fig. 4); and commonly used reporter genes are GFP, luciferase, protein A and acetate kinase [63-65]. For comparison, we give an example of MTB biotinylation which was achieved through proteomic engineering, in which the biotin carboxyl carrier protein (BCCP) gene was fused with mms13, whose co-expression led to the display of BCCP-Mms13 protein on the AMB-1 MM surface [66].

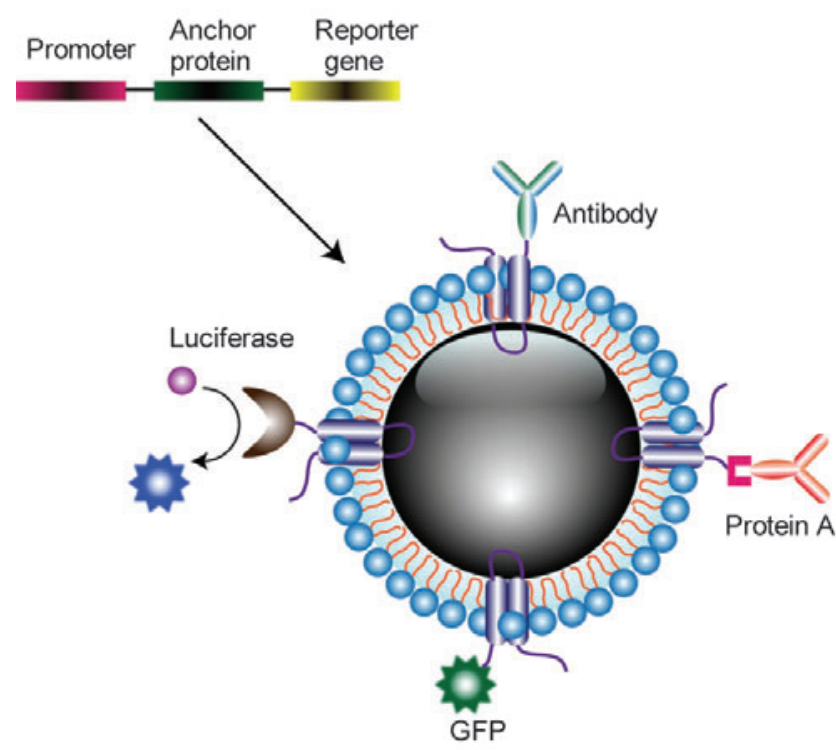

Figure 4 Schematic diagram of the preparation of functional MTBNPs using protein display techniques. To express a functional protein onto MTB-NPs, the functional protein gene was fused to an anchor protein gene. A plasmid containing the fusion gene was transformed into MTB. Expression efficiency is strongly dependent on the expression level of the anchor protein. Commonly applied fused proteins include luciferase, GFP, protein A, and different types of antibodies 
The 149 residues of BCCP could be recognized by the endogenous AMB-1 biotin ligase, which induced biotinylation in vivo. Compared with previous methods, this approach achieved site-specific biotinylation in one step. It is clean, biogenic, and free of by-product, and could be a prominent method to make biotinylated magnetite particles.

The fused protein can also work as an indicator to help evaluate the biological actions of MTBs. For instance, MagA can be fused with luciferase, which, upon interacting with luciferin, releases, bioluminescent signals that can be interpreted as a proliferation indicator, making it easy to decide the optimal growth conditions [3]. As already mentioned, since the reporter gene is expressed in a programmed manner with the anchoring protein, they can serve as probes to allow interrogation of the biological habits of MM proteins. For example, luciferase fused MagA, Mms13, and Mms16 have been expressed in MTBs. By comparing their corresponding luminescence intensities, their relative expression levels could be evaluated, showing that Mms13 were 400-1000 times more abundant on the particle surface than the other two, likely due to their high affinity to the magnetite surface, and thus making it a prominent anchor protein [67].

Although the magnetosomes themselves are of low toxicity, the associated bacterial endotoxin lipopolysaccharide (LPS) that is brought in during purification might contribute adverse effects. To address this issue, Matsunaga et al. recently suggested a technique to reconstruct the MTB-NP surface, with Mms13 being the selective anchoring protein and the only coating content. Owing to its strong interaction with the magnetite cores, Mms13 is highly retained on the MM. Therefore, detergent treatment, while stripping the other proteins associated with the MTB particles_-including LPS - does not affect retention of the Mms13 on the particle surface. The de-coated particles aggregate, but the solubility can be restored by the addition of phophatidylcholine. In this demonstration, Mms13 was fused with protein $A$, which survived the detergent treatment and washing cycles while still retaining the antibody immobilization capability [68].

Although it is convenient, it is not mandatory to take advantage of the lipid coating layer. Just as for functionalization of synthetic particles, exotic coating layers can be added. For instance, incubating MTB particles with aminopropyltriethoxysilane results in silane crosslinking and coagulation, yielding in silica coated particles that are hydrophilic and aminated. Matsunaga et al. immobilized glucose oxidase and uricase onto such particles by using glutaraldehyde as the crosslinking agent. Compared with conjugates made from synthetic magnetites or zinc ferrite particles, such particles showed enzyme activities about 40 times higher, and could be used for 5 cycles without loss of catalytic activity [69].

The high magnetization and surface-to-volume ratio ensure that MTB-NPs are effective agents in magnetic separation. For example, they have been applied to extract heavy metal cations, such as plutonium $(\mathrm{Pu})$, from waste water, due to their superior loading capacity [70]. Facilitated by the versatile ways to manipulate their surface features, the MTB-NPs can be tailored to only associate with certain targets, and when applied to a pool of mixed species, only the targets are immobilized onto the particles, and the target-bearing MTB-NPs can be isolated by an external magnetic field. The association between particles and biospecies can be a nonspecific physical interaction, with the most representative example being DNA or RNA isolation; they are highly negatively charged, and tend to be adsorbed onto positively charged particle surfaces. Positively charged MTB-NPs can be achieved by switching the coating layer to an amine abundant silica coating, as mentioned above [68], or, in a more effective and more controllable approach, by introducing dendrimers with different generations onto the particles [71]. When exposing such particles to a pool of various biomolecules, for example cell lysate, the DNA can be concentrated onto the particles and subsequently collected with high purity by magnetic extraction and finally recovered in appropriate buffer solutions [71]. However, such physical interactionbased bioseparation suffers from nonspecific adsorption issues and has limited usage. A better approach is to make the particles "smart" by loading them onto molecules which have a unique match with the target and will recognize and bound with 
it exclusively when in proximity. The streptavidin immobilized MTB particles, derived from the various biotinylation approaches mentioned above, are good starting materials, since they allow conjugation with a variety of antibodies for rendering specific targeting capability. For instance, Niemeyer et al. developed a novel immuno-PCR technology for antigen detection by utilizing such streptavidin magnetosome conjugates (Fig. 5) [72]. In their system, biotinylated antibody was first applied to the streptavidinmagnetosome conjugates, followed by the addition of targeting antigen and a second antibody which was specific to the antigen and was pre-conjugated with DNA fragments. The subjects recognize each other and immobilize onto the particle surface in a sandwich-like manner. After magnetic extraction, the conjugates were subjected to immuno-PCR which amplified the read-out (Fig. 5). In a demonstration with recombinant Hepatitis B surface antigen, the detection limit reached $320 \mathrm{pg} / \mathrm{mL}$ of HBsAg using such a Magneto Immuno-PCR (M-IPCR) system, which is about 100 times more sensitive than the analogous Magneto-ELISA method and is 25 times more sensitive than commercial synthetic magnetic microbeads.

If the antibodies are aimed at antigens that are over-expressed on certain cell surfaces, the conjugates can be accumulated on or within the cells, thus enabling cell separation. Such idea has been applied to E. coli extraction from bacterial suspensions [73] and mononuclear cell separation from peripheral blood [68]. For example, Mms13-protein A MTBs, have been applied to separate monocytes and B-lymophocytes from peripheral blood mononuclear cells (Fig. 6). The initial mononuclear cell mixture contained $24.2 \% \mathrm{CD} 14^{+}, 16.8 \% \mathrm{CD} 19^{+}$, and $17.1 \%$ $\mathrm{CD} 20^{+}$cells. However, by applying Mms13-protein A-MTB in conjunction with the corresponding antiCD IgG antibodies, the purities were all elevated above $95 \%$ after separation [68].

MTB particles can also serve as imaging probes. For example, biotinylated MTB particles have been applied to streptavidin coated substrates, and after incubating for some time, the unbound MTBs were washed off, leaving only those immobilized through specific biotin-streptavidin interactions. Subsequently, the substrate was subjected to magnetic force microscopy (MFM) for magnetic

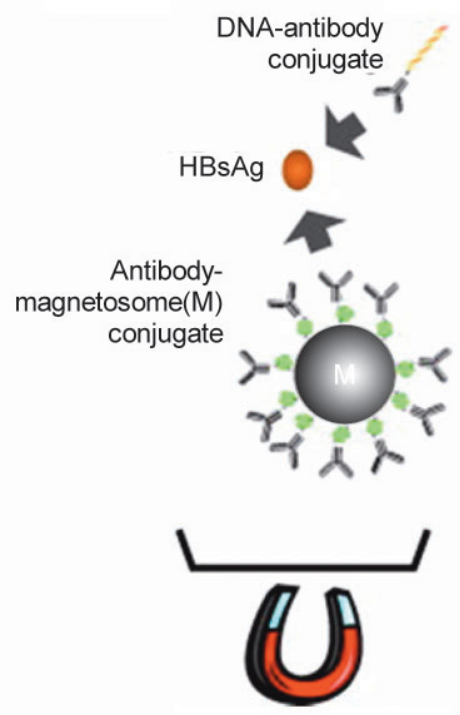

(a)

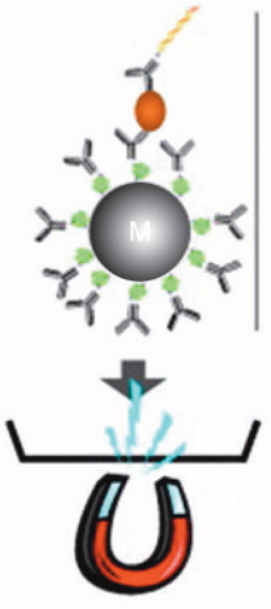

(b)

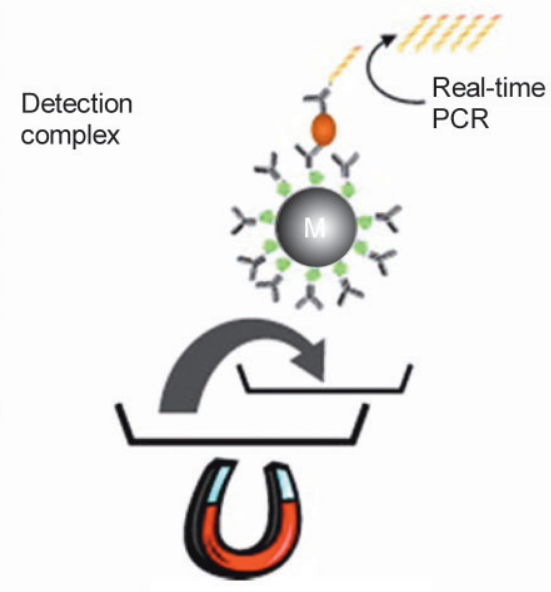

(c)

Figure 5 Schematic drawing of the Magneto Immuno-PCR (M-IPCR). MTB-NPs are loaded with antibody against $\mathrm{HBsAg}$, which are incubated with a serum sample containing HBsAg, as well as the second antibody and pre-conjugated with DNA. Due to the specific interaction, the HBsAg and the DNA-antibody will be immobilized onto the MTB-NPS in a sandwich-like structure, and can be separated by applying an external magnetic field. Subsequently, the NPs are resuspended and subjected to real-time PCR detection. Copyright (C) Elsevier Inc. Reproduced from Ref. [72] with permission 


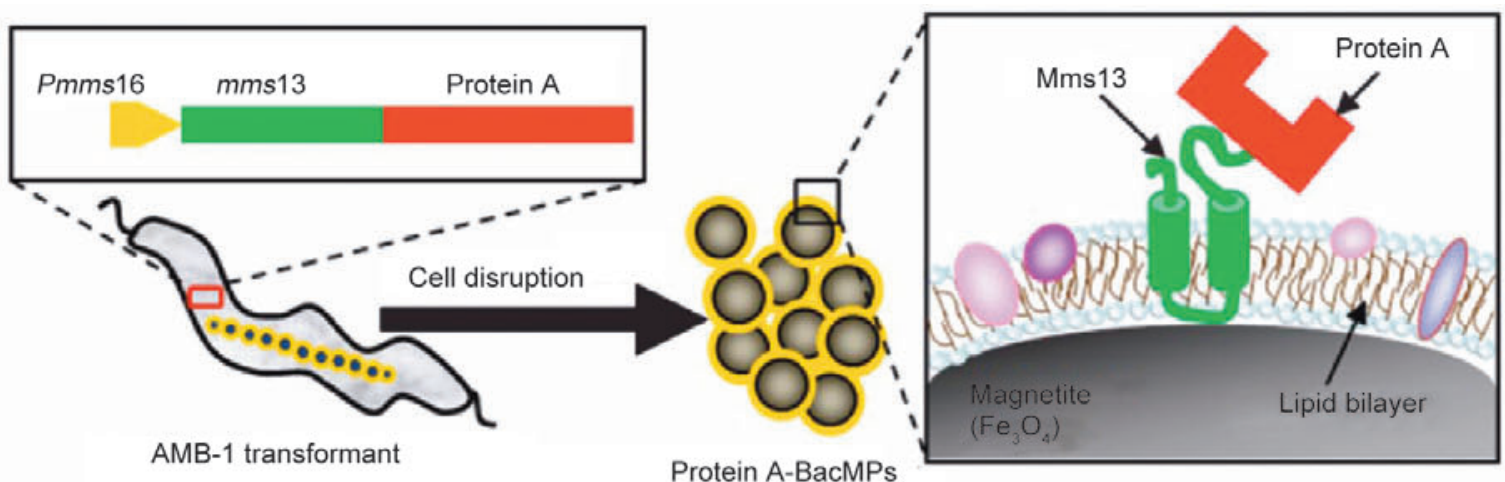

(a)

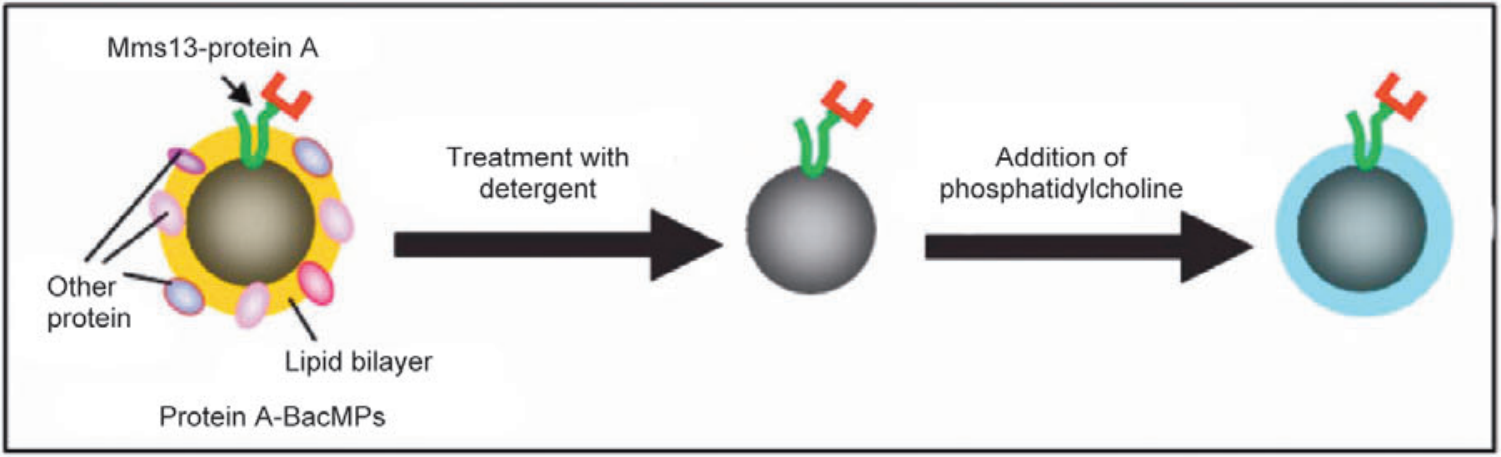

(b)

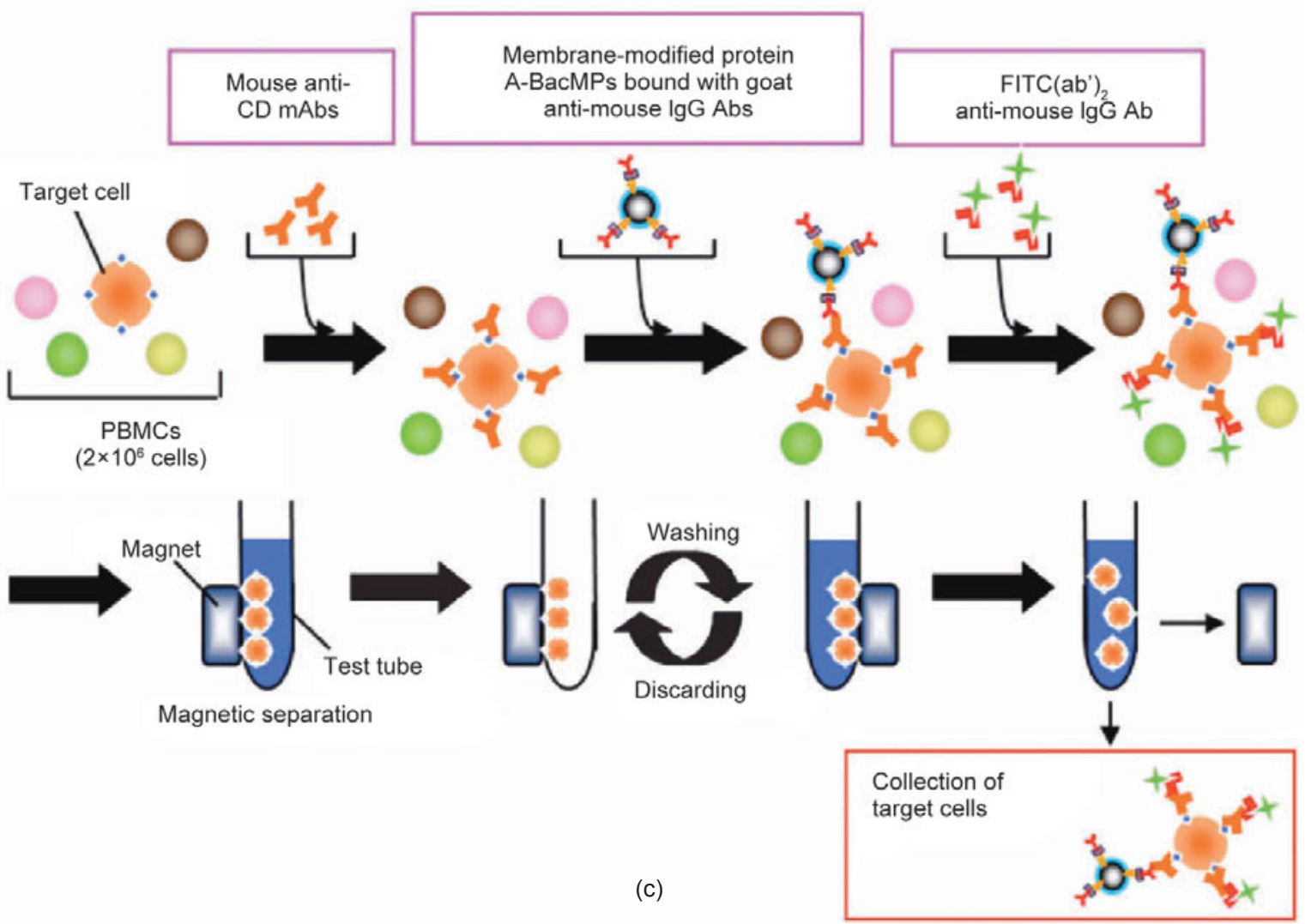

Figure 6 Schematic illustration of the detection procedure. Amplified PCR products were targeted for SNP detection. SNP was determined by measuring the fluorescence intensity of the probes liberated from MTB-NPs complexes by heating. Copyright () Wiley Periodicals, Inc., A Wiley Company. Reproduced from Ref. [68] with permission

(1) 
imaging. The advantage of using MTB-NPs is that these magnetic tags are potentially more sensitive than the conventionally applied optical tags. The detection limit of such method can be as low as 1 $\mathrm{pg} / \mathrm{mL}$, about 100 times more sensitive than that of fluorescence-signal-based detection techniques [74]. More interestingly, the MTB-NPs can be employed as MR imaging probes. As noted above, the transverse relaxivity $\left(r_{2}\right)$ of MTBs was evaluated as $146 \mathrm{mmol}^{-1} \cdot \mathrm{s}^{-1}$ as compared to that of 62 $\mathrm{mmol}^{-1} \cdot \mathrm{s}^{-1}$ for dextran coated synthetic particles [42], which is due to the higher magnetization of MTB particles; this potentially makes them better contrast agents in $T_{2}$-weighted MRI. Reichenbach et al. used MTBs to label macrophage cells for inflammation detection. The macrophage labeling was done $e x$ vivo by nonspecific uptake of MTB particles, and the resulting cells were injected into peritonitisbearing mice. Subsequent MRI scans found that the macrophage cells were populated in the colon area, which induced detectable signal drop on $T_{2}$ or $T_{2}{ }^{*}$ weighted maps [75]. Unfortunately, however, up to now, despite their superior properties, MTB crystals have rarely been utilized in MRI, which is mainly because of production limitations. On the other hand, however, it was recently found that one MM protein, MamA, alone might be sufficient to make mammalian cells capable of producing magnetic nanoparticles [76]. In this study, $\mathrm{Hu}$ et al. transfected the 293 FT cells with the mamA gene and showed that the resulting cells could produce magnetic particles. More surprisingly, even at the in vivo level, these transfected cells could utilize endogenous Fe resources to produce magnetite particles and induce detectable local signal drops. This finding suggests that mamA could become a powerful reporter gene, which, once transfected, could possibly turn any cell into a magnetite factory.

MTB particles have also been utilized as drug carriers. Li et al. loaded doxorubicin (DOX) onto MTB-NPs through covalent attachment and evaluated the ability of these particles to inhibit tumor growth. In a pilot study performed on $\mathrm{H} 22$ tumor-bearing mice, these DOX-loaded MTB-NPs showed a comparable tumor suppression rate to DOX alone ( $86.8 \%$ vs $78.6 \%)$, but with much lower cardiac toxicity. Although in this preliminary study, the particles were administrated subcutaneously into the solid tumor, the potential exists to magnetically manipulate these drug loaded MTB-NPs, making them accumulate and execute therapeutic effects only at disease sites [77]. The same group recently reported their efforts to utilize MTB-NPs for gene delivery, in which they managed to use PEI associated MTB-NPs to deliver $\beta$-galactosidase plasmids, at both in vitro and in vivo levels. It was claimed that such MTB-PEINP system is more efficient and less toxic compared with PEI alone [78]. Meanwhile, the possibility of MTB-NP-based hyperthermia therapy has been discussed $[79,80]$ and related studies are on-going.

\section{Conclusions and perspectives}

Since Richard P. Blakemore first discovered MTB under a microscope some 30 years ago, considerable progress has been made in understanding the mechanism and construction of such natural magnetic particle machinery. On the other hand, however, harnessing such particles and utilizing them as tools in versatile bioapplications, is still in its infancy. The greatest hurdle is availability, given that the currently utilized pyrolysis methods can make grams of synthetic nanoparticles with precise quality control. However, progress has been made on scaling up the production and it is now possible to make more than $10 \mathrm{mg}$ of MTB-NPs from each liter of culture media per day. Furthermore, there are many attributes of MTB-NPs that make them potentially important, at least as a complement to synthetic magnetic nanoparticles. First of all, their sizes are in a range that is difficult to achieve by artificial synthetic approaches. Secondly, the MTBNPs are innately coated with a lipid layer that confers physiological solubility and stability, which is critical for bio-applications and is sometimes the bottleneck for synthetic magnetic nanoparticles. Last but not least, their functions can be manipulated at the genomic and proteomic levels. Thanks to the recent breakthroughs at both production and biogenetic ends, more and more efforts have been directed to exploit the practical feasibility of MTB-NPs. Although most of these studies are still at the proof-of-concept 
level, the MTB-NPs have already demonstrated the potential to work as well as, or in some cases even better than, synthetic analogues. Meanwhile, ongoing efforts to elucidate the mechanism of such machinery could lead to more exciting findings that may further enrich and empower this platform.

\section{References}

[1] Blakemore, R. P. Magnetotactic bacteria. Annu. Rev. Microbiol. 1982, 36, 217-238.

[2] Arakaki, A.; Nakazawa, H.; Nemoto, M.; Mori, T.; Matsunaga, T. Formation of magnetite by bacteria and its application. J. R. Soc. Interface 2008, 5, 977-999.

[3] Bazylinski, D. A. Synthesis of the bacterial magnetosome: The making of a magnetic personality. Int. Microbiol. 1999, 2, 71-80.

[4] Bazylinski, D. A.; Frankel, R. B. Magnetosome formation in prokaryotes. Nat. Rev. Microbiol. 2004, 2, 217-230.

[5] Bazylinski, D. A. Structure and function of the bacterial magnetosome. Asm. News 1995, 61, 337-343.

[6] Komeili, A. Molecular mechanisms of magnetosome formation. Annu. Rev. Biochem. 2007, 76, 351-366.

[7] Thomas-Keprta, K. L.; Clemett, S. J.; Bazylinski, D. A.; Kirschvink, J. L.; McKay, D. S.; Wentworth, S. J.; Vali, H.; Gibson, E. K., Jr.; Romanek, C. S. Magnetofossils from ancient Mars: A robust biosignature in the martian meteorite ALH84001. Appl. Environ. Microbiol. 2002, 68, 3663-3672.

[8] Thomas-Keprta, K. L.; Clemett, S. J.; Bazylinski, D. A.; Kirschvink, J. L.; McKay, D. S.; Wentworth, S. J.; Vali, H.; Gibson, E. K., Jr.; McKay, M. F.; Romanek, C. S. Truncated hexa-octahedral magnetite crystals in ALH84001: Presumptive biosignatures. Proc. Natl. Acad. Sci. USA 2001, 98, 2164-2169.

[9] Thomas-Keprta, K. L.; Bazylinski, D. A.; Kirschvink, J. L.; Clemett, S. J.; McKay, D. S.; Wentworth, S. J.; Vali, H.; Gibson, E. K., Jr.; Romanek, C. S. Elongated prismatic magnetite crystals in ALH84001 carbonate globules: Potential Martian magnetofossils. Geochim. Cosmochim. Acta 2000, 64, 4049-4081.

[10] Weiss, B. P.; Kim, S. S.; Kirschvink, J. L.; Kopp, R. E.; Sankaran, M.; Kobayashi, A.; Komeili, A. Magnetic tests for magnetosome chains in Martian meteorite ALH84001. Proc. Natl. Acad. Sci. USA 2004, 101, 82818284.
[11] Prozorov, R.; Prozorov, T.; Mallapragada, S. K.; Narasimhan, B.; Williams, T. J.; Bazylinski, D. A. Magnetic irreversibility and the Verwey transition in nanocrystalline bacterial magnetite. Phys. Rev. B 2007, 76, 054406

[12] Bazylinski, D. A.; Moskowitz, B. M. Microbial biomineralization of magnetic iron minerals: Microbiology, magnetism and environmental significance. Geomicrobiol. Interact. Microbe. Mineral 1997, 35, 181-223.

[13] Frankel, R. B.; Blakemore, R. P.; Dearaujo, F. F. T.; Esquivel, D. M. S.; Danon, J. Magnetotactic bacteria at the geomagnetic equator. Science 1981, 212, 12691270.

[14] Blakemore, R. P.; Frankel, R. B.; Kalmijn, A. J. Southseeking magnetotactic bacteria in the southernhemisphere. Nature 1980, 286, 384-385.

[15] Simmons, S. L.; Bazylinski, D. A.; Edwards, K. J. Southseeking magnetotactic bacteria in the northern hemisphere. Science 2006, 311, 371-374.

[16] Frankel, R. B.; Bazylinski, D. A.; Johnson, M. S.; Taylor, B. L. Magneto-aerotaxis in marine coccoid bacteria. Biophys. J. 1997, 73, 994-1000.

[17] Smith, M. J.; Sheehan, P. E.; Perry, L. L.; O'Connor, K.; Csonka, L. N.; Applegate, B. M.; Whitman, L. J. Quantifying the magnetic advantage in magnetotaxis. Biophys. J. 2006, 91, 1098-1107.

[18] Gorby, Y. A.; Beveridge, T. J.; Blakemore, R. P. Characterization of the bacterial magnetosome membrane. J. Bacteriol. 1988, 170, 834-841.

[19] Tanaka, M.; Okamura, Y.; Arakaki, A.; Tanaka, T.; Takeyama, H.; Matsunaga, T. Origin of magnetosome membrane: Proteomic analysis of magnetosome membrane and comparison with cytoplasmic membrane. Proteomics 2006, 6, 5234-5247.

[20] Matsunaga, T.; Okamura, Y.; Fukuda, Y.; Wahyudi, A. T.; Murase, Y.; Takeyama, H. Complete genome sequence of the facultative anaerobic magnetotactic bacterium Magnetospirillum sp. strain AMB-1. DNA Res. 2005, 12, 157-166.

[21] Komeili, A.; Li, Z.; Newman, D. K.; Jensen, G. J. Magnetosomes are cell membrane invaginations organized by the actin-like protein MamK. Science 2006, 311, 242-245.

[22] Scheffel, A.; Gruska, M.; Faivre, D.; Linaroudis, A.; Plitzko, J. M.; Schuler, D. An acidic protein aligns magnetosomes along a filamentous structure in magnetotactic bacteria. Nature 2006, 440, 110-114. 
[23] Mclntosh, R.; Nicastro, D.; Mastronarde, D. New views of cells in 3D: An introduction to electron tomography. Trends Cell Biol. 2005, 15, 43-51.

[24] Komeili, A.; Vali, H.; Beveridge, T. J.; Newman, D. K. Magnetosome vesicles are present before magnetite formation, and MamA is required for their activation. Proc. Natl. Acad. Sci. USA 2004, 101, 3839-3844.

[25] Schuler, D. Genetics and cell biology of magnetosome formation in magnetotactic bacteria. FEMS Microbiol. Rev. 2008, 32, 654-672.

[26] Richter, M.; Kube, M.; Bazylinski, D. A.; Lombardot, T.; Glockner, F. O.; Reinhardt, R.; Schuler, D. Comparative genome analysis of four magnetotactic bacteria reveals a complex set of group-specific genes implicated in magnetosome biomineralization and function. J. Bacteriol. 2007, 189, 4899-4910.

[27] Schubbe, S.; Kube, M.; Scheffel, A.; Wawer, C.; Heyen, U.; Meyerdierks, A.; Madkour, M. H.; Mayer, F.; Reinhardt, R.; Schuler, D. Characterization of a spontaneous nonmagnetic mutant of Magnetospirillum gryphiswaldense reveals a large deletion comprising a putative magnetosome island. J. Bacteriol. 2003, 185, 5779-5790.

[28] Bazylinski, D. A.; Schubbe, S. Controlled biomineralization by and applications of magnetotactic bacteria. Adv. Appl. Microbiol. 2007, 62, 21-62.

[29] Ullrich, S.; Kube, M.; Schubbe, S.; Reinhardt, R.; Schuler, D. A hypervariable 130-kilobase genomic region of Magnetospirillum gryphiswaldense comprises a magnetosome island which undergoes frequent rearrangements during stationary growth. J. Bacteriol. 2005, 187, 7176-7184.

[30] Grunberg, K.; Wawer, C.; Tebo, B. M.; Schuler, D. A large gene cluster encoding several magnetosome proteins is conserved in different species of magnetotactic bacteria. Appl. Environ. Microbiol. 2001, 67, 4573-4582.

[31] Scheffel, A.; Schuler, D. The acidic repetitive domain of the Magnetospirillum gryphiswaldense MamJ protein displays hypervariability but is not required for magnetosome chain assembly. J. Bacteriol. 2007, 189, 6437-6446.

[32] Pradel, N.; Santini, C. L.; Bernadac, A.; Fukumori, Y.; $\mathrm{Wu}, \mathrm{L}$. F. Biogenesis of actin-like bacterial cytoskeletal filaments destined for positioning prokaryotic magnetic organelles. Proc. Natl. Acad. Sci. USA 2006, 103, 17485 -17489 .
[33] Scheffel, A.; Gardes, A.; Grunberg, K.; Wanner, G.; Schuler, D. The major magnetosome proteins MamGFDC are not essential for magnetite biomineralization in Magnetospirillum gryphiswaldense but regulate the size of magnetosome crystals. J. Bacteriol. 2008, 190, 377386.

[34] Thornhill, R. H.; Burgess, J. G.; Sakaguchi, T.; Matsunaga, T. A morphological classification of bacteria containing bullet-shaped magnetic particles. Fems. Microbiol. Lett. 1994, 115, 169-176.

[35] Bazylinski, D. A.; Garrattreed, A. J.; Frankel, R. B. Electron-microscopic studies of magnetosomes in magnetotactic bacteria. Micros. Res. Techniq. 1994, 27, 389-401.

[36] Han, L.; Li, S.; Yang, Y.; Zhao, F.; Huang, J.; Chang, J. Comparison of magnetite nanocrystal formed by biomineralization and chemosynthesis. J. Magn. Magn. Mater. 2007, 313, 236-242.

[37] Lins, U.; McCartney, M. R.; Farina, M.; Frankel, R. B.; Buseck, P. R. Crystal habits and magnetic microstructures of magnetosomes in coccoid magnetotactic bacteria. An. Acad. Bras. Cienc. 2006, 78, 463-474.

[38] Lins, U.; McCartney, M. R.; Farina, M.; Frankel, R. B.; Buseck, P. R. Habits of magnetosome crystals in coccoid magnetotactic bacteria. Appl. Environ. Microbiol. 2005, 71, 4902-4905.

[39] Muxworthy, A. R.; Williams, W. Critical singledomain/multidomain grain sizes in noninteracting and interacting elongated magnetite particles: Implications for magnetosomes. J. Geophys. Res. 2006, 111, B12S12.

[40] Heyen, U.; Schuler, D. Growth and magnetosome formation by microaerophilic Magnetospirillum strains in an oxygen-controlled fermentor. Appl. Microbiol. Biotechnol. 2003, 61, 536-544.

[41] Lee, J. H.; Huh, Y. M.; Jun, Y.; Seo, J.; Jang, J.; Song, H. T.; Kim, S.; Cho, E. J.; Yoon, H. G.; Suh, J. S.; Cheon, J. Artificially engineered magnetic nanoparticles for ultrasensitive molecular imaging. Nat. Med. 2007, 13, 95-99.

[42] Dunin-Borkowski, R. E.; McCartney, M. R.; Frankel, R. B.; Bazylinski, D. A.; Posfai, M.; Buseck, P. R. Magnetic microstructure of magnetotactic bacteria by electron holography. Science 1998, 282, 1868-1870.

[43] Staniland, S.; Ward, B.; Harrison, A.; van der Laan, G.; Telling, N. Rapid magnetosome formation shown by realtime X-ray magnetic circular dichroism. Proc. Natl. Acad. Sci. USA 2007, 104, 19524-19528. 
[44] Arakaki, A.; Webb, J.; Matsunaga, T. A novel protein tightly bound to bacterial magnetic particles in Magnetospirillum magneticum strain AMB-1. J. Biol. Chem. 2003, 278, 8745-8750.

[45] Moisescu, C.; Bonneville, S.; Tobler, D.; Ardelean, I.; Benning, L. G. Controlled biomineralization of magnetite $\left(\mathrm{Fe}_{3} \mathrm{O}_{4}\right)$ by Magnetospirillum gryphiswaldense. Mineral. Mag. 2008, 72, 333-336.

[46] Staniland, S.; Williams, W.; Telling, N.; Van Der Laan, G.; Harrison, A.; Ward, B. Controlled cobalt doping of magnetosomes in vivo. Nat. Nanotechnol. 2008, 3, 158162.

[47] Suzuki, T.; Okamura, Y.; Calugay, R. J.; Takeyama, H.; Matsunaga, T. Global gene expression analysis of ironinducible genes in Magnetospirillum magneticum AMB-1. J. Bacteriol. 2006, 188, 2275-2279.

[48] Xia, M.; Wei, J.; Lei, Y.; Ying, L. A novel ferric reductase purified from Magnetospirillum gryphiswaldense MSR-1. Curr. Microbiol. 2007, 55, 71-75.

[49] Noguchi, Y.; Fujiwara, T.; Yoshimatsu, K.; Fukumori, $Y$. Iron reductase for magnetite synthesis in the magnetotactic bacterium Magnetospirillum magnetotacticum. J. Bacteriol. 1999, 181, 2142-2147.

[50] Paoletti, L. C.; Blakemore, R. P. Iron reduction by aquaspirillum-magnetotacticum. Curr. Microbiol. 1988, 17, 339-342.

[51] Andrews, S. C.; Robinson, A. K.; Rodriguez-Quinones, F. Bacterial iron homeostasis. FEMS Microbiol. Rev. 2003, 27, 215-237.

[52] Schuler, D. Formation of magnetosomes in magnetotactic bacteria. J. Mol. Microbiol. Biotechnol. 1999, 1, 79-86.

[53] Faivre, D.; Bottger, L. H.; Matzanke, B. F.; Schuler, D. Intracellular magnetite biomineralization in bacteria proceeds by a distinct pathway involving membranebound ferritin and an iron(II) species. Angew. Chem. Int. Ed. Engl. 2007, 46, 8495-8499.

[54] Nies, D. H.; Silver, S. Ion Efflux systems involved in bacterial metal resistances. J. Indust. Microbiol. 1995, 14, 186-199.

[55] Paulsen, I. T.; Saier, M. H. A novel family of ubiquitous heavy metal ion transport proteins. J. Membrane Biol. 1997, 156, 99-103.

[56] Faivre, D.; Menguy, N.; Posfai, M.; Schuler, D. Environmental parameters affect the physical properties of fast-growing magnetosomes. Amer. Mineral. 2008, 93, 463-469.
[57] Bazylinski, D. A.; Frankel, R. B.; Heywood, B. R.; Mann, S.; King, J. W.; Donaghay, P. L.; Hanson, A. K. Controlled biomineralization of magnetite $\left(\mathrm{Fe}_{3} \mathrm{O}_{4}\right)$ and greigite $\left(\mathrm{Fe}_{3} \mathrm{~S}_{4}\right)$ in a magnetotactic bacterium. Appl. Environ. Microbiol. 1995, 61, 3232-3239.

[58] Kobayashi, A.; Kirschvink, J. L.; Nash, C. Z.; Kopp, R. E.; Sauer, D. A.; Bertani, L. E.; Voorhout, W. F.; Taguchi, T. Experimental observation of magnetosome chain collapse in magnetotactic bacteria: Sedimentological, paleomagnetic, and evolutionary implications. Earth Planet. Sci. Lett. 2006, 245, 538-550.

[59] Schuler, D.; Frankel, R. B. Bacterial magnetosomes: Microbiology, biomineralization and biotechnological applications. Appl. Microbiol. Biotechnol. 1999, 52, 464 $-473$.

[60] Sun, J. B.; Zhao, F.; Tang, T.; Jiang, W.; Tian, J. S.; Li, Y.; Li, J. L. High-yield growth and magnetosome formation by Magnetospirillum gryphiswaldense MSR-1 in an oxygen-controlled fermentor supplied solely with air. Appl. Microbiol. Biotechnol. 2008, 79, 389-397.

[61] Ceyhan, B.; Alhorn, P.; Lang, C.; Schuler, D.; Niemeyer, C. M. Semisynthetic biogenic magnetosome nanoparticles for the detection of proteins and nucleic acids. Small 2006, 2, 1251-1255.

[62] Tanaka, T.; Takeda, H.; Kokuryu, Y.; Matsunaga, T. Spontaneous integration of transmembrane peptides into a bacterial magnetic particle membrane and its application to display of useful proteins. Anal. Chem. 2004, 76, 3764-3769.

[63] Nakamura, C.; Kikuchi, T.; Burgess, J. G.; Matsunaga, T. Iron-regulated expression and membrane localization of the maga protein in Magnetospirillum sp strain Amb-1. J. Biochem. 1995, 118, 23-27.

[64] Matsunaga, T.; Sato, R.; Kamiya, S.; Tanaka, T.; Takeyama, H. Chemiluminescence enzyme immunoassay using protein A-bacterial magnetite complex. J. Magn. Magn. Mater. 1999, 194, 126-131.

[65] Matsunaga, T.; Togo, H.; Kikuchi, T.; Tanaka, T. Production of luciferase-magnetic particle complex by recombinant Magnetospirillum sp AMB-1. Biotechnol. Bioeng. 2000, 70, 704-709.

[66] Maeda, Y.; Yoshino, T.; Takahashi, M.; Ginya, H.; Asahina, J.; Tajima, H.; Matsunaga, T. Noncovalent immobilization of streptavidin on in vitro- and in vivobiotinylated bacterial magnetic particles. Appl. Environ. Microbiol. 2008, 74, 5139-5145. 
[67] Yoshino, T.; Matsunaga, T. Efficient and stable display of functional proteins on bacterial magnetic particles using Mms13 as a novel anchor molecule. Appl. Environ. Microbiol. 2006, 72, 465-471.

[68] Yoshino, T.; Hirabe, H.; Takahashi, M.; Kuhara, M.; Takeyama, H.; Matsunaga, T. Magnetic cell separation using nano-sized bacterial magnetic particles with reconstructed magnetosome membrane. Biotechnol. Bioeng. 2008, 101, 470-477.

[69] Matsunaga, T.; Kamiya, S. Use of magnetic particles isolated from magnetotactic bacteria for enzyme immobilization. Appl. Microbiol. Biotechnol. 1987, 26, 328-332.

[70] Bahaj, A. S.; Croudace, I. W.; James, P. A. B.; Moeschler, F. D.; Warwick, P. E. Continuous radionuclide recovery from wastewater using magnetotactic bacteria. J. Magn. Magn. Mater. 1998, 184, 241-244.

[71] Yoza, B.; Arakaki, A.; Matsunaga, T. DNA extraction using bacterial magnetic particles modified with hyperbranched polyamidoamine dendrimer. J. Biotechnol.y 2003, 101, 219-228.

[72] Wacker, R.; Ceyhan, B.; Alhorn, P.; Schueler, D.; Lang, C.; Niemeyer, C. M. Magneto immuno-PCR: A novel immunoassay based on biogenic magnetosome nanoparticles. Biochem. Biophys. Res. Commun. 2007, 357, 391-396.

[73] Nakamura, N.; Burgess, J. G.; Yagiuda, K.; Kudo, S.; Sakaguchi, T.; Matsunaga, T. Detection and removal of Escherichia coli using fluorescein isothiocyanate conjugated monoclonal-antibody immobilized on bacterial magnetic particles. Anal. Chem. 1993, 65, 2036 -2039 .
[74] Amemiya, Y.; Tanaka, T.; Yoza, B.; Matsunaga, T. Novel detection system for biomolecules using nanosized bacterial magnetic particles and magnetic force microscopy. J. Biotechnol. 2005, 120, 308-314.

[75] Hartung, A.; Lisy, M. R.; Herrmann, K. H.; Hilger, I.; Schuler, D.; Lang, C.; Bellemann, M. E.; Kaiser, W. A.; Reichenbach, J. R. Labeling of macrophages using bacterial magnetosomes and their characterization by magnetic resonance imaging. J. Magn. Magn. Mater. 2007, 311, 454-459.

[76] Zurkiya, O.; Chan, A. W.; Hu, X. MagA is sufficient for producing magnetic nanoparticles in mammalian cells, making it an MRI reporter. Magn. Reson. Med. 2008, 59, 1225-1231.

[77] Sun, J. B.; Duan, J. H.; Dai, S. L.; Ren, J.; Zhang, Y. D.; Tian, J. S.; Li, Y. In vitro and in vivo antitumor effects of doxorubicin loaded with bacterial magnetosomes (DBMs) on H22 cells: The magnetic bio-nanoparticles as drug carriers. Cancer Lett. 2007, 258, 109-117.

[78] Xiang, L.; Bin, W.; Huali, J.; Wei, J.; Jiesheng, T.; Feng, G.; Ying, L. Bacterial magnetic particles (BMPs)-PEl as a novel and efficient non-viral gene delivery system. J. Gene Med. 2007, 9, 679-690.

[79] Hergt, R.; Hiergeist, R.; Zeisberger, M.; Schuler, D.; Heyen, U.; Hilger, I.; Kaiser, W. A. Magnetic properties of bacterial magnetosomes as potential diagnostic and therapeutic tools. J. Magn. Magn. Mates. 2005, 293, 80 $-86$.

[80] Hergt, R.; Dutz, S. Magnetic particle hyperthermiabiophysical limitations of a visionary tumour therapy. J. Magn. Magn. Mater. 2007, 311, 187-192. 